an identical serotype and phage type ; the other infants found to be colonised with the same type had been born at about the same tirse to culture-negative mothers. These other babies had not been colonised at birth but had acquired the organism by the time they left hospital. Transmission might have been either via the hands of staff or direct from mother to baby. Mothers did, on occasion, handle each other's babies, although this was not encouraged. With our limited resources we could not swab all the staff on the postnatal wards at regular intervals as we did on the special-care baby unit. Given this limitation, 12 out of 21 cases of infant colonisation from non-maternal sources in these wards were linked by phage typing and serotyping to motherbaby index cases. In one cluster of culture-positive babies a member of staff was probably the source of transmission. The serotype III phage 11 strain colonised five of the staff of the special-care baby unit and then apparently disappeared. One of the staff carrying this strain had examined four babies on the postnatal wards who were later found to be colonised with an organism with the same characteristics. Possibly certain phage types of group B streptococci, as with other organisms such as Staphylococcus aureus, are associated with an increased capacity to spread. This possibility deserves further investigation. We cannot tell how many of the remaining babies acquired the organism from staff carriers. Anthony et $a^{4}$ also used phage typing to follow up the spread of group B streptococci among infant cohorts in a nursery. They did not, however, undertake a continuous survey of transmission of the organism, which is perhaps better done when the cohort system is not used.

Apart from during the first two months of the survey the prevalence of carriage of group B streptococci among the staff of the special-care baby unit was fairly constant $\left(27-33^{\circ}\right)$. During September, however, 12 of the 26 staff swabbed $\left(48^{\circ}{ }_{0}\right)$ were found to be carriers, of whom six had positive throat cultures, which was unusual. As mentioned above, five of the 12 carriers were colonised with group B streptococci serotype III, phage 11. During the study period there was little evidence of baby to baby or staff to baby transmission, and on only one occasion were two babies on the special-care baby unit found to be colonised with identical isolates. A similar organism was isolated at the same time from a member of staff.

Nosocomial transmission was slight in the special-care baby unit but considerable in the postnatal wards. This difference may be a reflection of the aseptic techniques possible in a small unit. The layout and fast turnover in the larger postnatal wards makes any aseptic regimen more difficult to enforce and procedures for baby-handling and handwashing often become compromised.

We thank the consultant obstetricians in the St Mary's Group for permission to study patients under their care, the medical and nursing staff whose co-operation made this study possible, and the Medical Research Council for financial support.

Requests for reprints should be addressed to Dr C S F Easmon, Bacteriology Department, St Mary's Hospital Medical School, London W2 1PG.

\section{References}

' Parker MT. Infections with group B streptococci. $\mathcal{F}$ Antimicrob Chemother $1975 ; 5$, suppl A :27-37.

${ }^{2}$ Baker CJ, Barrett FF. Transmission of group B streptococci among parturient women and their neonates. F Pediatr 1973;83:919-25.

${ }^{3}$ Stringer J. The development of a phage-typing system for group B streptococci. F Med Microbiol 1980;13:133.

4 Anthony BF, Okada DM, Hobel CJ. Epidemiology of the group B streptococcus: maternal and nosocomial sources for infant acquisitions. 7 Pediatr $1979 ; 95: 431-6$.

5 Boyer KM, Vogel LC, Gotoff SP, Gadzala CA, Stringer J, Maxted WR. Nosocomial transmission of bacteriophage type $7 / 11 / 12$ group $B$ streptococci in a special care nursery. Am f Dis Child 1980;134:964-6.

6 Aber RC, Allen N, Howell JT, Wilkinson HW, Facklam RR. Nosocomial transmission of group B streptococci. Pediatrics 1976;58:346-53.

Baker CJ, Clark DS, Barrett FF. Selective broth medium for isolation of group B streptococci. Applied Microbiol $1973 ; 26$ :884-5.

\& Islam AKMS. Rapid recognition of group B streptococci. Lancet 1977;i: 256-7.

9 Paredes A, Wong P, Mason EO. Nosocomial transmission of group B streptococci in a newborn nursery. Pediatrics $1977 ; \mathbf{5 9}: 674-82$.

(Accepted 9fune 1981)

\title{
Hypercalcaemia due to dihydrotachysterol treatment in patients with hypothyroidism after thyroidectomy
}

\author{
B-A LAMBERG, M J TIKKANEN
}

\begin{abstract}
Hypercalcaemia is a recognised complication of hypothyroidism. We describe three patients who developed hypercalcaemia after thyroidectomy when thyroid supplements were discontinued. They were treated with thyroxine, dihydrotachysterol, and calcium after operation, and in all three cases serum calcium concentrations remained constant during combined treatment. Thyroxine treatment was discontinued several weeks before a radioiodine scan was performed; dihydrotachysterol and calcium were continued throughout. Serum calcium
\end{abstract}

Third Department of Medicine, University of Helsinki, SF-00290 Helsinki 29, Finland

M J TIKKANEN, MD, senior lecturer in experimental endocrinology

Endocrine Research Laboratory, University of Helsinki, Finland B-A LAMBERG, MD, professor of endocrinology concentrations rose to hypercalcaemic levels in all cases.

Elimination of dihydrotachysterol from plasma may be delayed in hypothyroidism, resulting in hypervitaminosis $D$. It is advisable to reduce the dose of dihydrotachysterol and to check serum calcium concentrations regularly in patients whose thyroid treatment is interrupted.

\section{Introduction}

Hypercalcaemia is a rare complication of hypothyroidism. ${ }^{1}$ Our recent experience indicates that patients with postoperative hypoparathyroidism after total thyroidectomy for thyroid carcinoma are particularly likely to develop hypercalcaemia when vitamin $\mathrm{D}$ treatment is continued and thyroid treatment is interrupted for several weeks before radioiodine treatment. As this may be an important practical problem we describe our observations. 


\section{Case reports}

Case 1-A 44-year-old woman who had undergone total thyroidectomy for papillary thyroid carcinoma was treated with $200 \mu \mathrm{g}$ thyroxine (Thyroxin, Oriom), $0.4 \mathrm{mg}$ dihydrotachysterol, and $2 \mathrm{~g}$ calcium gluconate (Mega-Calcium, Sandoz) daily. To perform total-body radioiodine scanning we interrupted the thyroxine treatment but continued dihydrotachysterol and calcium treatment. After four weeks serum calcium concentrations rose to $3.66 \mathrm{mmol} / \mathrm{l}$ $(14.6 \mathrm{mg} / 100 \mathrm{ml})$, and the patient was referred to our hospital with nausea and headache. On admission serum calcium concentration was $3 \mathrm{mmol} / \mathrm{l}(12 \mathrm{mg} / 100 \mathrm{ml})$; serum thyroxine concentration $27 \mathrm{nmol} / 1(2 \cdot 1 \mu \mathrm{g} / 100 \mathrm{ml})$ (reference limits of the central laboratory in University Central Hospital, Helsinki: $60-160 \mathrm{nmol} / \mathrm{l}(4 \cdot 7-12 \cdot 4 \mu \mathrm{g} /$ $100 \mathrm{ml})$ ); the Sephadex uptake of triiodothyronine 0.82 ; and the free thyroxine index 23 (reference limits: 60-160). Further developments are shown in the figure. Dihydrotachysterol was restarted, and six months later the serum calcium concentration was $2.22 \mathrm{mmol} / \mathrm{l}$ $(8.9 \mathrm{mg} / 100 \mathrm{ml})$.

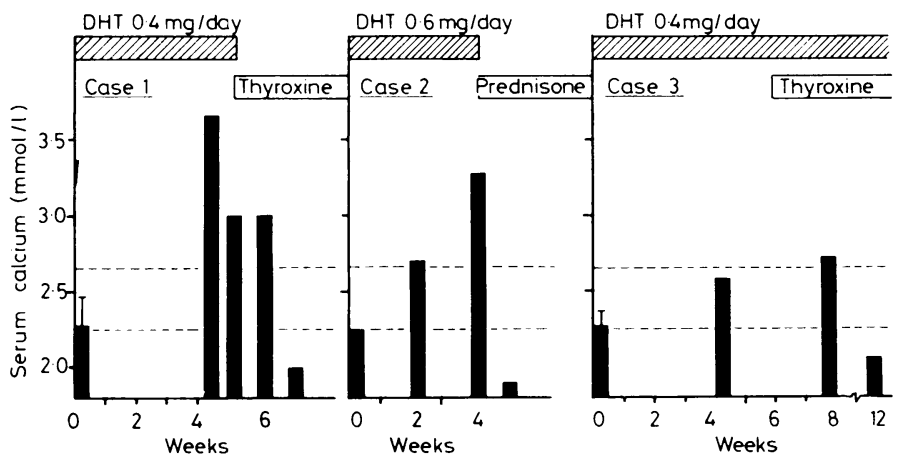

The effect of discontinuation of thyroxine treatment on serum calcium concentration. Zero level is represented by mean: SD of four (in case 2 only the mean of two) consecutive previous serum calcium determinations. Broken lines indicate upper $(2.65 \mathrm{mmol} / 1(10.6 \mathrm{mg} / 100 \mathrm{ml}))$ and lower $(2.25 \mathrm{mmol} / 1(9 \mathrm{mg} / 100 \mathrm{ml}))$ reference limits for serum calcium.

DHT $=$ Dihydrotachysterol

Conversion: SI to traditional units-Serum calcium: $1 \mathrm{mmol} / 1 \approx 4 \mathrm{mg}$ $100 \mathrm{ml}$.

Case 2-A 59-year-old woman was treated with thyroxine $(100 \mu \mathrm{g} /$ day) after total thyroidectomy for follicular thyroid carcinoma. Four weeks after operation her serum calcium concentration was $1.5 \mathrm{mmol} / 1$ $(6 \mathrm{mg} / 100 \mathrm{ml})$ and serum inorganic phosphate concentration $1.8 \mathrm{mmol} /$ $(5.6 \mathrm{mg} / 100 \mathrm{ml})$. Treatment with dihydrotachysterol was started with a dose of $0.8 \mathrm{mg} /$ day. After three weeks the serum calcium concentration was $2.7 \mathrm{mmol} / 1(10.8 \mathrm{mg} / 100 \mathrm{ml})$, and dihydrotachysterol was decreased to $0.6 \mathrm{mg}$ and thyroxine increased to $200 \mu \mathrm{g} /$ day. During the next two months serum calcium concentration was measured twice; on the first occasion it was $2.2 \mathrm{mmol} / 1(8.8 \mathrm{mg} /$ $100 \mathrm{ml}$ ) and on the second occasion $2.3 \mathrm{mmol} / 1(9.2 \mathrm{mg} / 100 \mathrm{ml})$. To perform total-body radioiodine scanning we interrupted the thyroxine treatment but continued dihydrotachysterol treatment. The serum calcium concentration started to rise, and she was admitted to hospital with pronounced clinical myxoedema, the free thyroxine index being 50 and the serum thyroid-stimulating hormone concentration $106 \mathrm{mU} / 1$ (normal concentration $<7.0 \mathrm{mU} / 1$ ). After treatment with prednisone $(30 \mathrm{mg} /$ day $)$ serum calcium concentration fell rapidly to hypocalcaemic levels. Since then, with thyroxine and dihydrotachysterol treatment, her calcium concentrations have been within normal range.

Case 3-A 48-year-old woman was treated with $250 \mu \mathrm{g}$ thyroxine daily after total thyroidectomy for papillary thyroid carcinoma. Postoperative hypoparathyroidism was treated with $0.4 \mathrm{mg}$ dihydrotachysterol per day. Eleven months after operation thyroxine treatment was interrupted to perform total-body radioiodine scanning, but dihydrotachysterol treatment was continued. Serum calcium concentration started to rise and was still raised two weeks after the thyroxine treatment had been restarted (see figure). Dihydrotachysterol was decreased to $0.2 \mathrm{mg} / \mathrm{day}$, and at later examinations the serum calcium concentration was about $2 \cdot 2 \mathrm{mmol} / 1(8.8 \mathrm{mg} / 100 \mathrm{ml})$.

\section{Discussion}

In all three patients serum calcium concentrations remained fairly constant and within normal ranges during the combined treatment with thyroxine and dihydrotachysterol. When thyroxine was discontinued serum calcium concentrations increased to hypercalcaemic levels. Two mechanisms that presumably contribute to the development of hypercalcaemia in some hypothyroid patients are increased calcium absorption from the gut and decreased glomerular infiltration." The serum concentration of 1,25-dihydroxycholecalciferol is increased in hypothyroidism, ${ }^{3}$ which may explain the increased intestinal absorption of calcium. This resembles the accumulation of carotene, the fat-soluble vitamin-A precursor that causes the characteristic yellowish tint of the skin in hypothyroidism. ${ }^{4}$ Thus a possible explanation for the hypercalcaemia in our patients is delayed elimination of dihydrotachysterol from the plasma in the hypothyroid state, resulting in hypervitaminosis D. Accordingly, it is important to reduce the dose of dihydroatchysterol and to measure the serum calcium concentration regularly when thyroxine substitution is interrupted in patients with hypoparathyroidism after total thyroidectomy.

\section{References}

${ }^{1}$ Lowe CE, Bird ED, Thomas WC. Hypercalcaemia in myxedema. $\mathcal{f}$ Clin Endocrinol Metab 1961;22:261-7.

2 Lekkerkerker JFF, Doorenbos $\mathrm{H}$. The influence of thyroid hormone on calcium absorption from the gut in relation to urinary calcium excretion. Acta Endocr (Kbh) 1973;73:672-80.

${ }^{3}$ Bouillon R, Muls E, De Moor P. Influence of thyroid function on the serum concentration of 1,25-dihydroxyvitamin $\mathrm{D}_{3} . \mathcal{F}$ Clin Endocrinol Metab 1980;51:793-7.

${ }^{1}$ Rivlin RS. Vitamin metabolism. In: Werner SC, Ingbar SH, eds. The thyroid. New York: Harper and Row, 1978:878-83.

(Accepted 9 fune 1981)
HEMP is so well known to every good housewife in the country, that I shall not need to write any description of it. It is sown in the very end of March, or beginning of April, and is ripe in August or September.

It is a plant of Saturn, and good for something else, you see, than to make halters only. The seed of Hemp consumes wind, and by too much use thereof disperses it so much that it dries up the natural seed for procreation; yet, being boiled in milk and taken, helps such as have a hot dry cough. The Dutch make an emulsion out of the seed, and give it with good success to those that have the jaundice, especially in the beginning of the disease, if there be no ague accompanying it, for it opens obstructions of the gall, and causes digestion of choler. The emulsion or decoction of the seed stays lasks and continual fluxes, eases the cholic, and allays the troublesome humours in the bowels, and stays bleeding at the mouth, nose, or other places, some of the leaves being fried with the blood of them that bleed, and so given them to eat. It is held very good to kill the worms in men or beasts; and the juice dropped in the ears kills worms in them; and draws forth earwigs, or other living creatures gotten into them. The decoction of the root allays inflammations of the head, or any other parts: the herb itself, or the distilled water thereof doth the like. The decoction of the root eases the pains of the gout, the hard humours of knots in the joints, the pains and shrinking of the sinews, and the pains of the hips. The fresh juice mixed with a little oil and butter, is good for any place that hath been burnt with fire, being thereto applied. (Nicholas Culpeper (1616-54) The Complete Herbal, 1850.) 